\title{
Synthesis of the Galactosyl Derivative of Gluconic Acid With the Transglycosylation Activity of $\beta$-Galactosidase
}

\author{
Aleksandra Wojciechowska ${ }^{1 *}$, Robert Klewicki ${ }^{1}$, Michał Sójka ${ }^{1}$ and Elżbieta Klewicka ${ }^{2}$ \\ ${ }^{1}$ Institute of Food Technology and Analysis, Faculty of Biotechnology and Food Sciences, \\ Lodz University of Technology, Stefanowskiego 4/10, PL-90-924 Łódź, Poland \\ ${ }^{2}$ Institute of Fermentation Technology and Microbiology, Faculty of Biotechnology and Food Sciences, \\ Lodz University of Technology, Wólczańska 171/173, PL-90-924 Łódź, Poland
}

Received: April 7, 2016

Accepted: November 29, 2016

\begin{abstract}
Summary
Bionic acids are bioactive compounds demonstrating numerous interesting properties. They are widely produced by chemical or enzymatic oxidation of disaccharides. This paper focuses on the galactosyl derivative of gluconic acid as a result of a new method of bionic acid synthesis which utilises the transglycosylation properties of $\beta$-galactosidase and introduces lactose as a substrate. Products obtained in such a process are characterised by different structures (and, potentially, properties) than those resulting from traditional oxidation of disaccharides. The aim of this study is to determine the effect of selected parameters (concentration and ratio of substrates, dose of the enzyme, time, $\mathrm{pH}$, presence of salts) on the course of the reaction carried out with the enzymatic preparation Lactozym, containing $\beta$-galactosidase from Kluyveromyces lactis. Research has shown that increased dry matter content in the baseline solution (up to $50 \%$, by mass per volume) and an addition of $\mathrm{NaCl}$ contribute to higher yield. On the other hand, reduced content of the derivative is a result of increased $\mathrm{pH}$ from 7.0 to 9.0 and an addition of magnesium and manganese salts. Moreover, exceeding the $\beta$-galactosidase dose over approx. $35000 \mathrm{U}$ per $100 \mathrm{~g}$ of lactose also leads to reduced yield of the process. The most favourable molar ratio of sodium gluconate to lactose is 2.225:0.675. Depending on the conditions of the synthesis, the product concentration ranged between 17.3 and $118.3 \mathrm{~g} / \mathrm{L}$ of the reaction mixture, which corresponded to the mass fraction of $6.64-23.7 \%$ of dry matter. The data obtained as a result of the present study may be useful for designing an industrial process.
\end{abstract}

Key words: gluconic acid, $\beta$-galactosidase, transglycosylation, lactose

\section{Introduction}

From the chemical perspective, bionic acids belong to the group of aldobionic acids. They are obtained from corresponding disaccharides (e.g. lactose, maltose or melibiose) in the process of chemical or enzymatic oxidation (1). However, chemical methods are generally considered to be energy-intensive. Additionally, they require the use of expensive and harmful catalysts and may generate many by-products (2). Currently, selective oxidation of saccharides is achieved with catalysts including $\mathrm{Cr}^{6+}(3)$, $\mathrm{Au}, \mathrm{Pd}$ and $\mathrm{Pt}$ deposited on a carrier such as aluminium oxide or titanium dioxide (4). The application of gold nanoparticles recovered from end-of-life electronic equipment seems a novel and interesting idea in such a process (5). Bionic acids are also obtained using biotechnological

\footnotetext{
*Corresponding author: Phone: +48 42631 3465; E-mail: aleksandra.wojciechowska@dokt.p.lodz.pl 
methods. For instance, preparations containing lactose-oxidising enzymes can be used, such as cellobiose dehydrogenase or glucose-fructose dehydrogenases. The main advantages of these methods include high conversion of lactose (close to $100 \%$ ) and high selectivity of biocatalysts. On the other hand, they are time-consuming, and inactivation of enzymes poses a serious problem (6). Another option when applying biotechnological methods is to use whole microbial cells. The bacteria of Pseudomonas genus (i.e. P. taetrolens) are able to oxidise lactose and maltose with no requirement of previous hydrolysis. Two enzymes participate in that process: lactose dehydrogenase and lactonase (7). Lactobionic acid may also be obtained with acetic acid bacterium Acetobacter orientalis isolated from the upper layer of the Caucasian fermented milk, sold in Japan as Caspian Sea yogurt (8). It is worth mentioning that in the case of lactobionic acid, it is not only purified lactose that may be used as a substrate for the synthesis, but also lactose-containing whey, which is a waste product in the process of cheese production. The drawback of microbiological methods is that microorganisms can be subject to nutrient depletion or metabolic overflow. As a result, an irreversible physiological response caused by stress may occur. Despite that, fed-batch cultivation has become a standard operating mode in biotechnological lactobionic acid production (9). In terms of the methods enabling separation of lactobionic acid (extraction, precipitation and adsorption with ion-exchange resins), ion-exchange chromatography is preferred (2). In 2007 (no newer data is available) the market for lactobionic acid was estimated at 15 000-17 000 tonnes per year, with a forecast of a $5 \%$ annual growth rate $(6,10)$. The prospects for lactobionic acid (and other bionic acids as well) are promising thanks to the properties of such compounds. In fact, lactobionic acid has been long applied in medicine as a key ingredient of a solution used for preservation of tissues and organs for transplantation (11). Generally, bionic acids are used in pharmaceutical products as carriers and stabilisers, but also as components improving bioactive properties of these products. Some examples include the use of lactobionic acid as a solubilising agent for clarithromycin (12) and as an ingredient of eye drops applied in order to alleviate corneal oedema and inflammation (13). Complexes of maltobionic acid and iron are applied in supplementary treatment of anaemia (14). The cosmetic industry is also interested in the antioxidant and anti-ageing properties of bionic acids. These compounds have an exfoliating effect, but as polyhydroxy acids they cause less intense irritation than other alpha hydroxy acids (lactic or citric acid). Lactobionic and maltobionic acids may be used in products recommended for dry and sensitive skin, acne rosacea and atopic dermatitis (1). Antioxidant properties of bionic acids (15) and their derivatives (e.g. galactosyl-chitosan (16)) are also highly valued in the food industry. It was demonstrated that lactobionic acid slows down the ageing of bread and thus allows to maintain a soft and flexible texture of crumb (17). In dairy products, the compound may provide acidity and improve organoleptic properties (18). An addition of this acid to meat products results in smaller loss of water in the process of freezing, thawing or cooking, and thus allows to obtain higher yield of the final product (19). Moreover, bionic acids increase absorp- tion of mineral compounds. Their calcium salts may enrich chewing gums and oral compositions (for greater strength of tooth enamel), as well as supplements and milk drinks (20). Bionic acids probably also have some prebiotic properties (21).

The application of transgalactosylation may be an interesting method of obtaining bionic acids. In that case, the process consists in transferring a galactosyl residue onto a corresponding sugar acid with $\beta$-galactosidase. No data regarding the use of that method for the synthesis of bionic acids are available in the literature. The transglycosylation activity of that enzyme has been used mostly for production of galactooligosaccharides or lactulose (22), but also for production of galactosyl derivatives of xylose (23), sorbitol (24), glycerol (25), and other substances of potential biological activity (e.g. salicin galactoside (26)). It should be underlined that the pursuit of synthesis optimisation has constituted one of the most important aspects of research.

The aim of this study is to determine the effect of certain selected factors on the course of the synthesis reaction of the galactosyl derivative of gluconic acid. The following parameters are analysed: concentration and molar ratio of substrates (lactose and sodium gluconate), the amount of the enzymatic preparation, $\mathrm{pH}$, and the presence of selected salts.

\section{Materials and Methods}

\section{Materials}

Lactozym 3000 L HP-G, a $\beta$-galactosidase (EC 3.2.1.23) from Kluyveromyces lactis, was supplied by Novozymes A/S (Bagsvaerd, Denmark). Lactose was purchased from Bayerische Milchindustrie eG (Landshut, Germany). Gluconic acid sodium salt was purchased from Merck (Darmstadt, Germany). Lactobionic acid was purchased from Carl Roth GmbH + Co.KG (Karlsruhe, Germany). Sodium hydroxide was purchased from Eurochem BGD Sp. z.o.o. (Tarnów, Poland). Sodium chloride and potassium chloride were purchased from $\mathrm{POCH}$ (Gliwice, Poland). Magnesium chloride $\left(\mathrm{MgCl}_{2} \cdot 6 \mathrm{H}_{2} \mathrm{O}\right)$, manganum chloride $\left(\mathrm{MnCl}_{2}\right.$. $\left.4 \mathrm{H}_{2} \mathrm{O}\right)$ and sulphuric acid were purchased from Chempur (Piekary Śląskie, Poland). Glucose and galactose were purchased from Sigma-Aldrich (St. Louis, MO, USA). A reagent for determination of glucose concentration was purchased from BioMaxima S.A. (Lublin, Poland).

\section{Synthesis of galactosyl derivative of gluconic acid}

In order to determine the effect of various dry matter contents, $35600 \mathrm{U}$ of $\beta$-galactosidase per $100 \mathrm{~g}$ of lactose were added to $100 \mathrm{~mL}$ of a solution containing 20,30, 40 and $50 \mathrm{~g}$ of the mixture of sodium gluconate and lactose at the molar ratio of 1.9:1. The reaction was carried out in the solution with $\mathrm{pH}=6.9-7.0$ (adjusted with $0.25 \mathrm{M}$ $\mathrm{NaOH})$ at $(37 \pm 1){ }^{\circ} \mathrm{C}$ for $9 \mathrm{~h}$. A volume of $1 \mathrm{~mL}$ of the reaction mixture was collected at 1-hour intervals.

In order to determine the effect of various doses of the enzyme, 7170, 14 200, 21 400, 28 600, 35600 and 42800 $\mathrm{U}$ of $\beta$-galactosidase per $100 \mathrm{~g}$ of lactose were added to $100 \mathrm{~mL}$ of a solution containing $50 \mathrm{~g}$ of the mixture of sodium gluconate and lactose at the molar ratio of 1.9:1. 
In order to determine the effect of various molar ratios of sodium gluconate and lactose, $21400 \mathrm{U}$ of $\beta$-galactosidase per $100 \mathrm{~g}$ of lactose were added to $100 \mathrm{~mL}$ of a solution containing $50 \mathrm{~g}$ of the mixture of sodium gluconate and lactose at the molar ratio of 2.45:0.45, 2.225:0.675, 1.9:1, 1.675:1.225, 1.45:1.45 and 1:1.9.

In order to determine the effect of the presence of selected salts, $21400 \mathrm{U}$ of $\beta$-galactosidase per $100 \mathrm{~g}$ of lactose were added to $100 \mathrm{~mL}$ of a solution containing $50 \mathrm{~g}$ of the mixture of sodium gluconate and lactose at the molar ratio of 1.9:1. The reaction was carried out in the presence of $0.1 \mathrm{M} \mathrm{NaCl}, 0.5 \mathrm{M} \mathrm{NaCl}, 1 \mathrm{M} \mathrm{NaCl}, 1 \mathrm{M} \mathrm{KCl}, 100 \mathrm{mM}$ $\mathrm{MgCl}_{2}, 1 \mathrm{M} \mathrm{MgCl}_{2}, 100 \mathrm{mM} \mathrm{MnCl}$ or $1 \mathrm{M} \mathrm{MnCl}_{2}$.

In order to determine the effect of various $\mathrm{pH}$ values, $21400 \mathrm{U}$ of $\beta$-galactosidase per $100 \mathrm{~g}$ of lactose were added to $100 \mathrm{~mL}$ of a solution containing $50 \mathrm{~g}$ of the mixture of sodium gluconate and lactose at the molar ratio of 1.9:1. The $\mathrm{pH}$ value of the solution was maintained at 6.97, 7.4-7.5, 7.9-8.0, 8.4-8.5 and 8.9-9.0 (adjusted with 2 and $0.25 \mathrm{M} \mathrm{NaOH})$.

\section{Determination of the content of galactosyl derivative of gluconic acid with the HPLC method}

In order to inactivate the enzyme, a 1-mL sample of the reaction mixture collected for analysis was introduced to approx. $30 \mathrm{~mL}$ of boiling water and boiling was maintained for $1 \mathrm{~min}$. After cooling down to room temperature, the solution was transferred to a $50-$ or $100-\mathrm{mL}$ measuring flask and filled up with water. Then, the content of the flask was filtered. The obtained filtrate was passed through a cationite-filled column (Amberlite IR120 hydrogen form; Sigma-Aldrich, St. Loius, MO, USA). The first fraction $(3 \mathrm{~mL})$ was discarded, and the second one (3 $\mathrm{mL}$ ) was collected for HPLC-UV-DAD analysis (Smartline PDA Detector 2800; Knauer GmbH, Berlin, Germany). Separation of compounds was completed using two Aminex HPX-87H (Bio-Rad, Richmond, CA, USA) columns combined in a series, and a mobile phase of $5 \mathrm{mM} \mathrm{H}_{2} \mathrm{SO}_{4}$. The flow rate was $0.6 \mathrm{~mL} / \mathrm{min}$, and temperature was 40 ${ }^{\circ} \mathrm{C}$. Detection was carried out at the wavelength of 210 $\mathrm{nm}$. Considering high resemblance of the structures, the concentration of the galactosyl derivative of gluconic acid was determined based on the standard of lactobionic acid.

\section{MS analysis of the synthesis product}

The post-reaction mixture was subjected to the mass spectrum analysis with the QExactive Orbitrap detector (Thermo Scientific, Waltham, MA, USA). The sample was directly introduced into the detector (flow rate $10 \mu \mathrm{L} /$ $\mathrm{min})$. The negative ion mode was used. The following source parameters were applied: ion spray voltage 3.00 $\mathrm{kV}$, capillary temperature $300{ }^{\circ} \mathrm{C}$, sheath gas and auxiliary gas flow rates 30 and $5 \mathrm{AU} / \mathrm{min}$.

\section{Determination of the content of saccharides with the HPLC method}

A sample of $1 \mathrm{~mL}$ of the reaction mixture was introduced to approx. $30 \mathrm{~mL}$ of boiling water and boiling was maintained for $1 \mathrm{~min}$. After cooling down to room tem- perature, the solution was transferred to a $50-$ or $100-\mathrm{mL}$ measuring flask and filled up with water. Then, the content of the flask was filtered. The obtained filtrate was passed through a column with cationite (Amberlite IR120 hydrogen form; Sigma-Aldrich) and anionite (Amberlite IRA-67 free base; Sigma-Aldrich). The first fraction $(3 \mathrm{~mL})$ was discarded, and the second one ( $3 \mathrm{~mL})$ was collected for the HPLC analysis (RI Detector 2300; Knauer GmbH). The contents of saccharides were determined with the use of Aminex HPX87C column from Bio-Rad (Hercules, CA, USA) and a water mobile phase. The flow rate was 0.5 $\mathrm{mL} / \mathrm{min}$, and temperature was $85^{\circ} \mathrm{C}$.

\section{Determination of $\beta$-galactosidase activity}

The unit of activity (U) is defined as the amount of the enzyme that releases $1 \mu \mathrm{mol}$ of glucose in $1 \mathrm{~min}$, under the following conditions: $4.75 \%$ (by mass per volume) of lactose (sodium-potassium phosphate buffer, $\mathrm{pH}=6.9$ ), temperature $37^{\circ} \mathrm{C}$, and reaction time $30 \mathrm{~min}$ (27). A volume of $9.6 \mathrm{~mL}$ of lactose solution and $0.4 \mathrm{~mL}$ of the solution of the enzymatic preparation Lactozym 3000 L HP-G (Novozymes A/S, Bagsværd, Denmark) at the concentration of $1 \mathrm{~mL} / \mathrm{L}$ were used for the reaction. The mixture was incubated for $30 \mathrm{~min}$ at $37^{\circ} \mathrm{C}$. A 4-mL sample of the hydrolysate was collected and added to $5 \mathrm{~mL}$ of boiling distilled water for inactivation of the enzyme. Boiling was maintained for $3 \mathrm{~min}$. After cooling down to room temperature, the solution was transferred to a $10-\mathrm{mL}$ measuring flask and filled up with water. The content of the flask was filtered. Glucose concentration in the sample was determined using the glucose test from BioMaxima S.A. To $1000 \mu \mathrm{L}$ of the reagent, $10 \mu \mathrm{L}$ of the sample or glucose standard were added (the reagent sample contained only $1000 \mu \mathrm{L}$ of the reagent). After $10 \mathrm{~min}$ of incubation at 25 ${ }^{\circ} \mathrm{C}$, the absorbance was read at $\lambda=500 \mathrm{~nm}$ for test samples and standard samples, against the reagent sample.

\section{Results and Discussion}

\section{Determination of the transgalactosylation product}

So far, studies on the use of the transglycosylation activity of $\beta$-galactosidase have been mostly focused on the production of galactooligosaccharides (28). Lactose has often been used as a donor, and the role of an acceptor has been played by the saccharides present in the reaction environment, which leads to the formation of oligosaccharides of various structures. In the present study, lactose is a donor of the galactosyl group, and gluconic acid (as sodium salt) is an acceptor. The use of a substance that has more than one hydroxyl group in its structure as an acceptor leads to possible formation of more than one galactosyl derivative. In the case of sodium gluconate, there are five potential sites for attachment of a galactose molecule. One possibility is to create the $\beta-1,4$ bond and thus lead to the formation of lactobionic acid (4-O- $\beta$-galactopyranosyl-D-gluconic acid). However, the comparison of chromatographic profiles (HPLC-UV-DAD) of the post-reaction mixture containing the product of transgalactosylation and the lactobionic acid standard (Fig. 1) indicates that the said acid is not the main product under the applied synthesis conditions (retention times were 15.50 
and $15.80 \mathrm{~min}$, respectively). It should be noted that, according to literature, in transglycosylation reactions galactose preferentially binds to the primary hydroxyl group of the acceptor. Examples of products meeting that relation include: $\beta$-D-galactopyranosyl-( $1 \rightarrow 1)$-D-fructose (using $\beta$-galactosidase from Kluyveromyces lactis) (29), 3-O- $\beta$-D-galactopyranosyl-glycerol (Kluyveromyces lactis; 25) or salicin galactoside (Aspergillus oryzae; 26). It may be assumed that in the studied case that combination will also be prevailing, and so the dominant fraction of the product is most probably 6-O- $\beta$-galactopyranosyl-D-gluconic acid. Moreover, the MS analysis (Fig. 2) confirmed the presence of a compound with the molecular mass of $358 \mathrm{~g} / \mathrm{mol}$ (signal $\mathrm{m} / \mathrm{z}=357.10$ in the negative mode) in the post-reaction mixture.

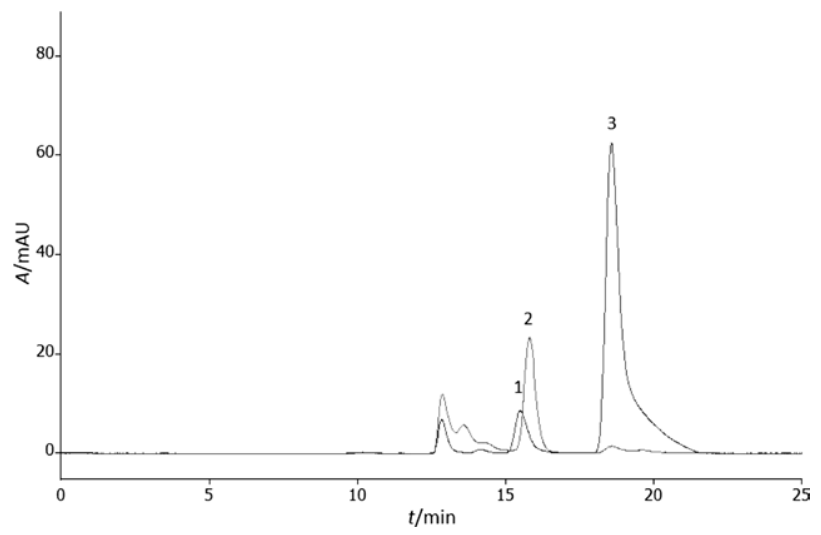

Fig. 1. A typical chromatogram (HPLC-UV-DAD) of the post-reaction mixture and the lactobionic acid standard. Peaks: $1=$ galactosyl derivative of gluconic acid (15.50 $\mathrm{min}), 2=$ lactobionic acid (15.80 $\mathrm{min})$, and $3=$ gluconic acid (18.60 $\mathrm{min})$

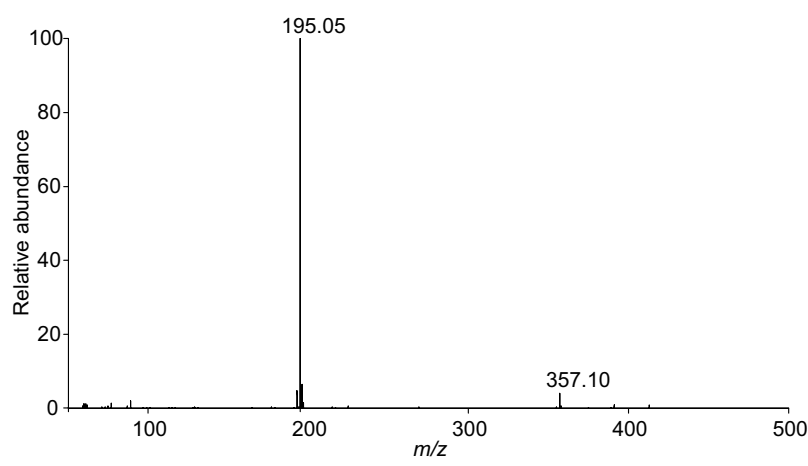

Fig. 2. Mass spectrum of the post-reaction mixture: $m / z=357.10$ (negative mode): galactosyl derivative of gluconic acid $(M=358$ $\mathrm{g} / \mathrm{mol}), m / z=195.05$ (negative mode): gluconic acid $(M=196.1 \mathrm{~g} /$ $\mathrm{mol})$

\section{Effect of selected factors on the course of the process}

The use of a baseline solution with a higher content of dry matter (with maintenance of the same dose of the enzymatic preparation per lactose content) resulted in increased final amount of the galactosyl derivative of gluconic acid. It was noted that double dry matter content (increase from 20 to $40 \%$, by mass per volume) in the baseline mixture caused the increase in the dry matter content of the product from 8.7 to $14.6 \%$ (Fig. 3). Increased concentration of substrates and increased ratio of products translates into a higher amount of the product obtained on a single occasion from the defined volume of solution (17.4 and $58.4 \mathrm{~g} / \mathrm{L}$, respectively). Increasing the dry matter content beyond $50 \%$ (by mass per volume) was limited by the solubility of the substrates. According to literature data, describing the synthesis of galactooligosaccharides with the use of $\beta$-galactosidase, the favourable effect of increased dry matter content in the baseline solution is based on the reduced activity of water and a shift of balance towards the synthesis reaction, thus reducing the intensity of hydrolysis of transglycosylation products. This translates into increased yield of synthesis in more condensed solutions (30).

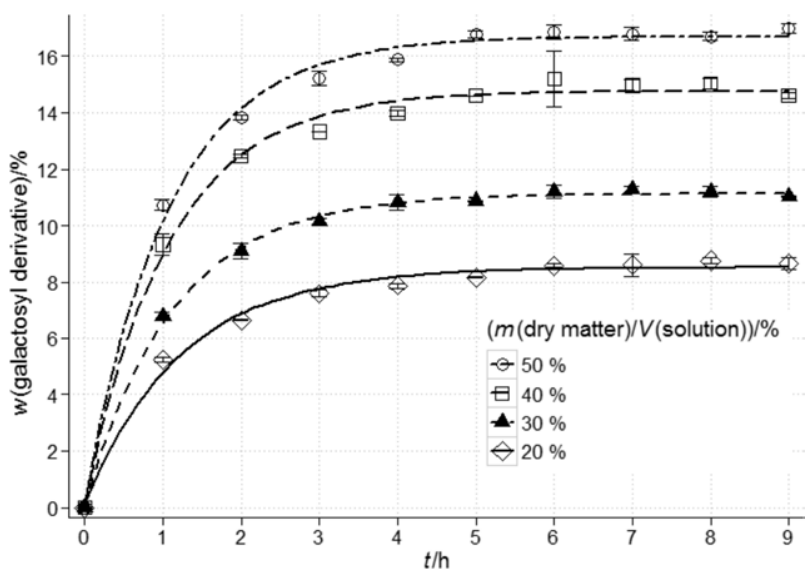

Fig. 3. Changes in the content of galactosyl derivative of gluconic acid on dry mass basis (\%) during synthesis in a solution containing a mixture of sodium gluconate and lactose at the molar ratio of 1.9:1, depending on the applied dry matter content (in $\%$, by mass per volume). Reaction conditions: $t=(37 \pm 1)$ ${ }^{\circ} \mathrm{C}, \mathrm{pH}=6.9-7.0$, and enzyme amount ( $\beta$-galactosidase from Kluyveromyces lactis) of $35600 \mathrm{U}$ per $100 \mathrm{~g}$ of lactose

One of the most important parameters analysed in the case of enzymatic reactions is the dose of an enzymatic preparation. Over $20 \%$ content of the galactosyl derivative was achieved at doses of 14200 and $21400 \mathrm{U}$ per 100 $\mathrm{g}$ of lactose (Fig. 4). Increasing the amount of the enzymatic preparation increased the rate of the reaction in the initial stage (particularly during the first hour), but at the amounts of $28600 \mathrm{U}$ per $100 \mathrm{~g}$ of lactose and higher, a lower final content of the product was noted. That phenomenon is associated with intensified hydrolysis of transglycosylation products after consumption of a major part of the basic substrate (lactose), and it was noted in previously published studies, e.g. on the synthesis of galactosyl derivatives of polyols (31) and oligosaccharides (32).

The molar ratio of substrates may also have a significant impact on the final content of transglycosylation products. Results reported by Wei et al. (25) may be an example here. They achieved higher yield of galactosylglycerol synthesis $(116.47 \mathrm{mg} / \mathrm{mL})$ when using glycerol in the amount exceeding ten times the galactose content. In 


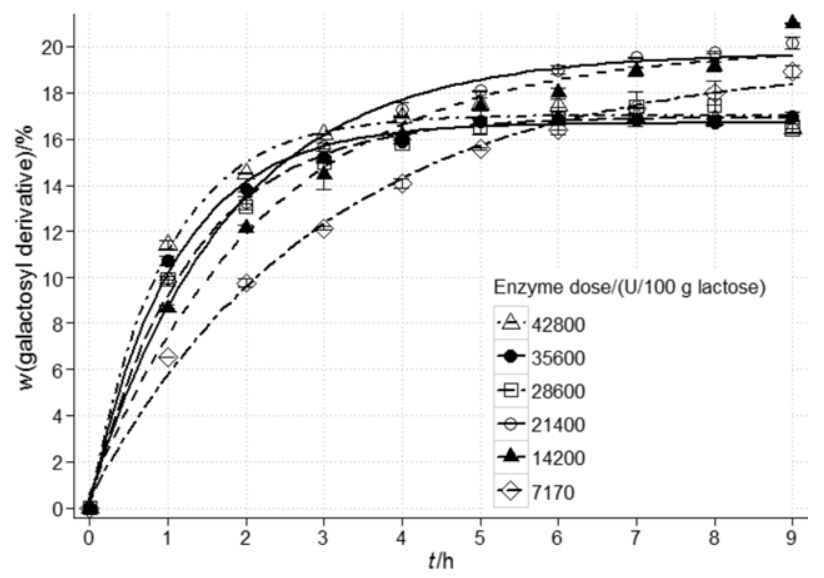

Fig. 4. Changes in the content of galactosyl derivative of gluconic acid on dry mass basis during synthesis in a $50 \%$ (by mass per volume) solution containing a mixture of sodium gluconate and lactose at the molar ratio of 1.9:1, depending on the dose of the enzyme ( $\beta$-galactosidase from Kluyveromyces lactis). Reaction conditions: $t=(37 \pm 1)^{\circ} \mathrm{C}$, and $\mathrm{pH}=6.9-7.0$

the study on the gluconic acid derivative, the initial ratio of sodium gluconate and lactose was 1.9:1. The ratio was selected based on the previous studies on production of galactosyl derivatives of polyols (sorbitol, xylitol and erytritol) (31). In the case of the galactosyl derivative of gluconic acid, the highest product content (i.e. $21.3 \%$ of dry matter obtained from the $50 \%$, by mass per volume, solution) was achieved following the modification of the sodium gluconate to the lactose ratio to 2.225:0.675 (Fig. 5). A further increase of the gluconic acid sodium salt molar fraction in the mixture caused reduction of the amount of the synthesised product.

The $\mathrm{pH}$ of the solution is another important parameter affecting the activity and modus operandi of $\beta$-galactosidase. The use of $\mathrm{pH}$ different than optimum for the activity of the enzyme may favour the synthesis of transglycosylation products as a result of modifications within

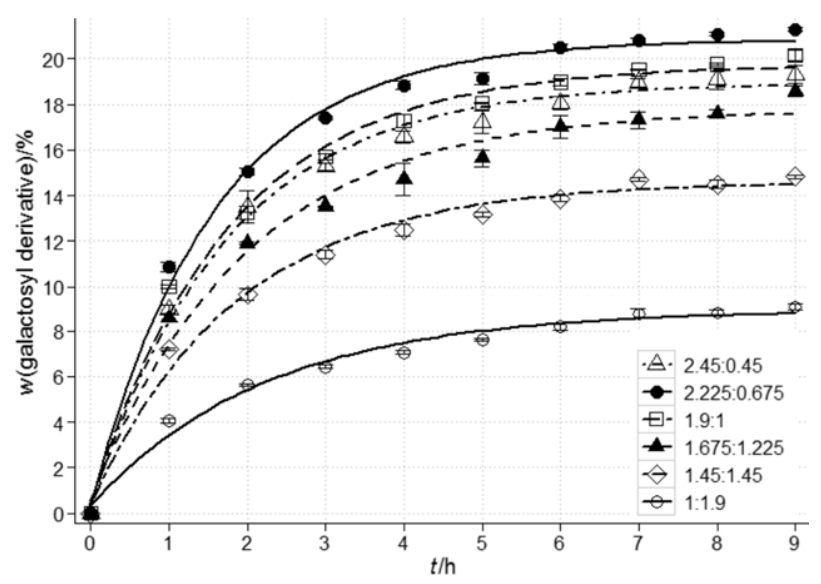

Fig. 5. Changes in the content of galactosyl derivative of gluconic acid on dry mass basis during synthesis in a $50 \%$ (by mass per volume) solution, depending on the applied molar ratio of substrates (sodium gluconate/lactose). Reaction conditions: $t=(37 \pm 1){ }^{\circ} \mathrm{C}, \mathrm{pH}=6.9-7.0$, and enzyme amount $(\beta$-galactosidase from Kluyveromyces lactis) of $21400 \mathrm{U}$ per $100 \mathrm{~g}$ of lactose the enzyme active site (33). Studies on galactooligosaccharides performed by Martínez-Villaluenga et al. (32) demonstrated that the increase of $\mathrm{pH}$ from 6.5 to 7.5 resulted in the extension of the time necessary to achieve the maximum trisaccharide content, but at the same time increased the trisaccharide mass fraction from 15.9 to 17.1 $\%$. In the case of the synthesis of gal-sorbitol, increasing the $\mathrm{pH}$ of the reaction mixture from 6.5 to 9.0 caused a 9 $\%$ increase of the product content (24). Contrary to the above-mentioned results, no presence of the gluconic acid derivative was detected in the post-reaction mixture at $\mathrm{pH}=9.0$. Increasing the $\mathrm{pH}$ from 7.0 to 8.5 resulted in a significant reduction of the galactosyl derivative of gluconic acid content by as much as $67.0 \%$ (Fig. 6).

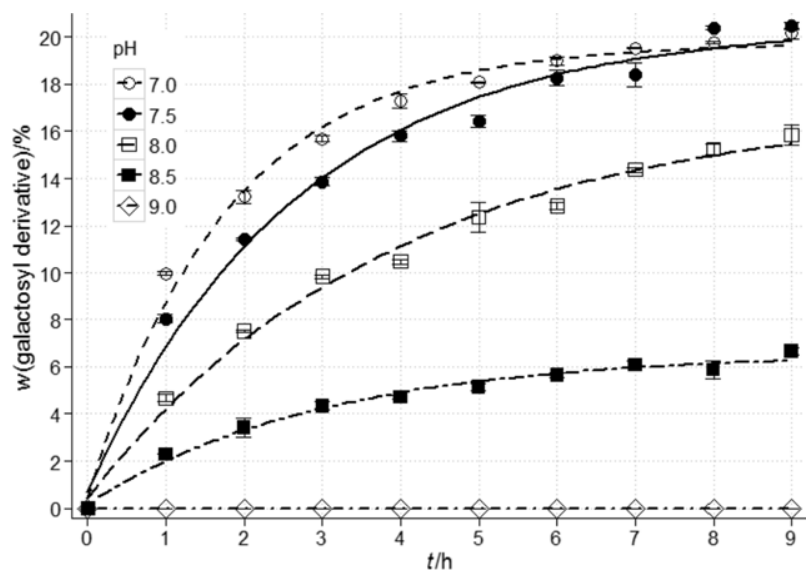

Fig. 6. Changes in the content of galactosyl derivative of gluconic acid on dry mass basis during synthesis in a $50 \%$ (by mass per volume) solution containing a mixture of sodium gluconate and lactose at the molar ratio of 1.9:1, depending on the $\mathrm{pH}$ of the solution. Reaction conditions: $t=(37 \pm 1){ }^{\circ} \mathrm{C}$, and enzyme amount ( $\beta$-galactosidase from Kluyveromyces lactis) of $21400 \mathrm{U}$ per $100 \mathrm{~g}$ of lactose

The last factor changed during the synthesis of the galactosyl derivative of gluconic acid was the presence and concentration of salt (Fig. 7). Expected changes in the course of the reaction would be associated with the reduced activity of water in the solution, as a result of salt dissolution. In our study, increasing the $\mathrm{NaCl}$ concentration resulted in an increased content of the galactosyl derivative of gluconic acid in dry matter. With the use of a 1 $\mathrm{M} \mathrm{NaCl}$ solution, an increase of approx. $17.5 \%$ was observed. However, the addition of $1 \mathrm{M} \mathrm{KCl}$ had no significant effect on the course of reaction. In the case of $1 \mathrm{M}$ $\mathrm{MnCl}_{2}$, a change of consistence made sample collection for the analysis impossible. As regards literature data, synthesis of gal-sorbitol carried out in $0.25-0.75 \mathrm{M} \mathrm{NaCl}$ solution resulted in an approx. $11 \%$ increase of the product content (24). A similar effect was achieved by Fortun and Colas (34), who synthesised the galactosyl derivative of phenylethanol with the use of an enzyme from Aspergillus oryzae in the presence of $0.5 \mathrm{M}$ lithium chloride. Another aspect associated with the addition of salt is a possibility of enzyme activation or inhibition by particular ions. Among activators of $\beta$-galactosidase from Kluyveromyces lactis, the literature mentions $\mathrm{Mg}^{2+}$ and $\mathrm{Mn}^{2+}$ (35). However, in the studies performed by Pawlak-Szu- 
kalska et al. (36) on $\beta$-galactosidase from Arthrobacter sp. $32 \mathrm{cB}, \mathrm{Mn}^{2+}$ ions had an inhibitory effect. In the synthesis of the galactosyl derivative of gluconic acid, the addition of both $\mathrm{MgCl}_{2}$ and $\mathrm{MnCl}_{2}$ resulted in reduced yield of the product. The use of $1 \mathrm{M} \mathrm{MgCl}$ solution resulted in the reduction of derivative content by $12.9 \%$.

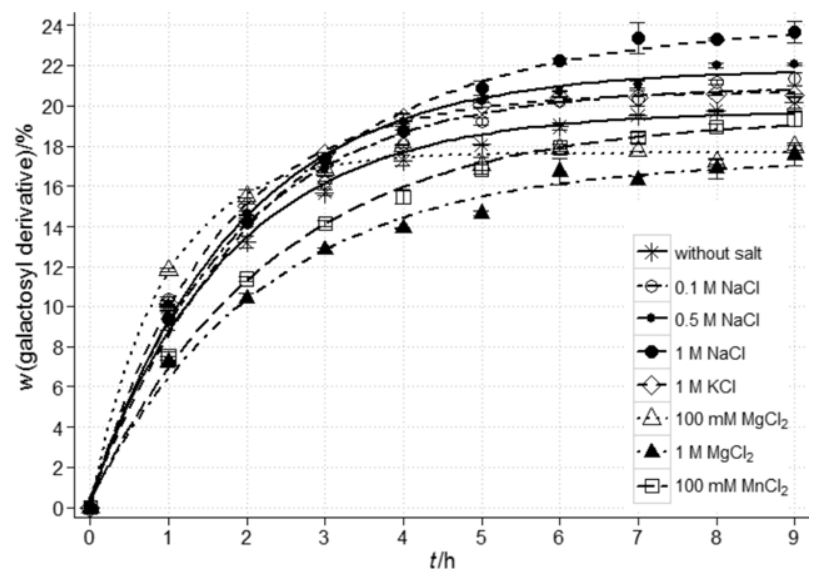

Fig. 7. Changes in the content of galactosyl derivative of gluconic acid on dry mass basis during synthesis in a $50 \%$ (by mass per volume) solution containing a mixture of sodium gluconate and lactose at the molar ratio of 1.9:1, depending on the presence of selected salts in various concentrations. Reaction conditions: $t=(37 \pm 1)^{\circ} \mathrm{C}, \mathrm{pH}=6.9-7.0$, and enzyme dose ( $\beta$-galactosidase from Kluyveromyces lactis) of $21400 \mathrm{U}$ per $100 \mathrm{~g}$ of lactose

Of course, the galactosyl derivative of gluconic acid is not the only product of transgalactosylation present in the reaction mixture. Galactooligosaccharides (GOS) also occur. For example, in the hydrolysate containing $21 \%$ of galactosyl derivative of gluconic acid in dry matter, GOS content on dry mass basis amounted to $2.2 \%$. Additionally, there were other saccharides in the solution (in \% on dry mass basis): disaccharides (including lactose) 6.5, galactose 8.8 , glucose 17.3 and unreacted sodium gluconate about 44.0 .

\section{Process yield}

It should be stressed that the achieved production yield of the galactosyl derivative of gluconic acid of approx. $21 \%$ using the $50 \%$ (by mass per volume) baseline solution (corresponding to $105 \mathrm{~g} / \mathrm{L}$ of post-reaction mixture) may be considered satisfactory in comparison with reports regarding other transglycosylation products with $\beta$-galactosidase from Kluyveromyces lactis. The highest gal-sorbitol content achieved with $35 \%$ (by mass per volume) baseline solution was $16.8 \%$ (24). Shen et al. (29) noted $15.4 \mathrm{~g} / \mathrm{L}$ of lactulose and $47.5 \mathrm{~g} / \mathrm{L}$ of allo-lactulose (approx. 3.9 and $11.9 \mathrm{~g} / 100 \mathrm{~g}$ on insoluble dry mass basis, respectively, calculated from the data in the article) obtained from initial concentrations of $200 \mathrm{~g} / \mathrm{L}$ of each lactose and fructose. Higher yields were achieved in the case of the galactooligosaccharide synthesis: Guerrero et al. (22) reported the yield of up to $28 \%$ (using $40 \%$ substrates solution), and Iliev and Vasileva (37) reported the yield as high as $41 \%$ (using $30 \%$ lactose solution).
As for the maximum productivity of the process (understood as the amount of a derivative obtained from a particular volume of a solution) of $118 \mathrm{~g} / \mathrm{L}$, it is comparable to the higher ranges noted for the synthesis of lactobionic acid. Concentration of the substrate (lactose) solution, and the applied production technique are important factors affecting that value. Productivity amounting to 3.2 $\mathrm{g} / \mathrm{L}$ (approx. $32 \mathrm{~g}$ per $100 \mathrm{~g}$ of lactose; calculated from the data in the article) was achieved by Goderska et al. (38) using oxidoreductase from Zymomonas mobilis expressed in Escherichia coli. In the experiments (with gold nanoparticles as a catalyst) performed by Borodina and Mirgorod (5), the value was approx. $27.3 \mathrm{~g} / \mathrm{L}$ (yield of $76 \%$ ). The productivity comparable to that achieved by us (approx. $100 \mathrm{~g} / \mathrm{L}$ ) was noted by Kiryu et al. (8) using Acetobacter orientalis isolated from Caspian Sea yogurt. Using a gold-based catalyst, Mirescu and Prüße (4) obtained approx. $107 \mathrm{~g}$ (approx. $100 \%$ of dry matter) of lactobionic acid in 1 $\mathrm{L}$ of the reaction mixture (calculated from the data in the article). There are literature reports indicating even higher productivity levels of $164 \mathrm{~g} / \mathrm{L}$ (yield of $82 \%$ ) obtained with the use of Pseudomonas taetrolens (9), and over 210 $\mathrm{g} / \mathrm{L}$ (approx. $72 \mathrm{~g}$ per $100 \mathrm{~g}$ of lactose, calculated from the data in the article) with the use of $\mathrm{Pd} / \mathrm{C}$ catalyst (39). It should be stressed that the time necessary to achieve the maximum content of the galactosyl derivative of gluconic acid (5-9 h) was closer to the lactobionic acid synthesis times with the use of chemical catalysts $(2 \mathrm{~h}$ by Borodina and Mirgorod (5) and $3.33 \mathrm{~h}$ by Mäki-Arvela et al. (39)) than to those reported for biotechnological methods $(24 \mathrm{~h}$ by Goderska et al. (38), from 40 to over $90 \mathrm{~h}$ by Kiryu et al. (8), and $80 \mathrm{~h}$ by Alonso et al. (9)). Thus, the facts mentioned above indicate that the application of transgalactosylation for the production of the galactosyl derivative of gluconic acid may be promising.

\section{Conclusions}

The highest content of the galactosyl derivative of gluconic acid was obtained using the $50 \%$ (by mass per volume) solution ( $21.3 \%$ on dry mass basis) with the molar ratio of sodium gluconate and lactose of 2.225:0.675. Increasing the amount of the enzymatic preparation above a certain value (approx. $21400 \mathrm{U}$ per $100 \mathrm{~g}$ of lactose) leads to reduced synthesis yield. However, a higher content of the dry matter in the baseline solution increases the concentration of the final product. Contrary to galactooligosaccharides, increased $\mathrm{pH}$ caused partial $(\mathrm{pH}=$ $8.0)$ or total $(\mathrm{pH}=9.0)$ inhibition of the reaction. An addition of $\mathrm{NaCl}$ resulted in increased content of the product in the post-reaction mixture (up to $17.5 \%$ in the case of the $1 \mathrm{M}$ solution). On the other hand, the addition of $\mathrm{Mg}^{2+}$ and $\mathrm{Mn}^{2+}$ caused reduction in the synthesis yield of the gluconic acid derivative.

\section{References}

1. Green BA, Yu RJ, Van Scott EJ. Clinical and cosmeceutical uses of hydroxyacids. Clin Dermatol. 2009;27:495-501. https://doi.org/10.1016/j.clindermatol.2009.06.023

2. Alonso S, Rendueles M, Díaz M. Bio-production of lactobionic acid: current status, applications and future prospects. 
Biotechnol Adv. 2013;31:1275-91.

https://doi.org/10.1016/j.biotechadv.2013.04.010

3. Roldán V, González JC, Santoro M, García S, Casado N, Olivera $\mathrm{S}$, et al. Kinetics and mechanism of the oxidation of disaccharides by $\mathrm{Cr}^{\mathrm{vI}}$. Can J Chem. 2002;80:1676-86. https://doi.org/10.1139/v02-187

4. Mirescu A, Prüße U. A new environmental friendly method for the preparation of sugar acids via catalytic oxidation on gold catalysts. Appl Catal B: Environ. 2007;70:644-52. https://doi.org/10.1016/j.apcatb.2006.01.017

5. Borodina VG, Mirgorod YA. Catalytic synthesis lactobionic acid. J Nano-Electron Phys. 2014;6:03052.

6. Gutiérrez LF, Bazinet L, Hamoudi S, Belkacemi K. Production of lactobionic acid by means of a process comprising the catalytic oxidation of lactose and bipolar membrane electrodialysis. Sep Purif Technol. 2013;109:23-32. https://doi.org/10.1016/j.seppur.2013.02.017

7. Nishizuka Y, Hayaishi O. Enzymic formation of lactobionic acid from lactose. J Biol Chem. 1962;237:2721-8.

8. Kiryu T, Yamauchi K, Masuyama A, Ooe K, Kimura T, Kiso $\mathrm{T}$, et al. Optimization of lactobionic acid production by Acetobacter orientalis isolated from Caucasian fermented milk, 'Caspian Sea yogurt'. Biosci Biotechnol Biochem. 2012;76:361363.

https://doi.org/10.1271/bbb.110608

9. Alonso S, Rendueles M, Díaz M. Feeding strategies for enhanced lactobionic acid production from whey by Pseudomonas taetrolens. Bioresour Technol. 2013;134:134-42. https://doi.org/10.1016/j.biortech.2013.01.145

10. Affertsholt-Allen T. Market developments and industry challenges for lactose and lactose derivatives. Presentation from IDF Symposium 'Lactose and its Derivatives', Moscow, Russia; 2007. Available from: http://lactose.ru/present/1Tage_ Affertsholt-Allen.pdf

11. Sumimoto R, Kamada N. Lactobionate as the most important component in UW solution for liver preservation. Transplant Proc. 1990;22:2198-2199.

12. Zakeri-Milani P, Mousavian-Fathi N, Ghanbarzadeh S, Zarrintan $\mathrm{MH}$, Valizadeh H. Application of lactobionic acid and nonionic surfactants as solubilizing agents for parenteral formulation of clarithromycin. Adv Pharm Bull. 2012;2:3742.

https://doi.org/10.5681/apb.2012.006

13. Cavallo G, Stagni M, Sodo E. Ophthalmic composition based on lactobionic acid useful for reducing corneal edema and inflammation. European patent EP 2494954 B1. 2014.

14. Autuori M, Bosi D, Lapini SA, Marchi E. New low molecular weight complexes between iron and maltobionic acid, use thereof for intramuscular or subcutaneous administration in the treatment of anemic states, and new pharmaceutical compositions adapted for these uses. European patent EP 2580227 B1. 2014.

15. Nielsen PM. Production of maltobionate. European patent EP2185717 B1. 2011.

16. Ruiz Matute AI, Cardelle-Cobas A, García-Bermejo AB, Montilla A, Olano A, Corzo N. Synthesis, characterization and functional properties of galactosylated derivatives of chitosan through amide formation. Food Hydrocolloid. 2013; 33:245-55.

https://doi.org/10.1016/j.foodhyd.2013.03.016

17. Oe K, Kimura T. Aging inhibitor for bread. Japanese patent JP 2011177121 A. 2011.

18. Lynglev GB, Koka R, Mehnert DW, Fritsch RJ. Method for producing a fermented dairy product. European patent EP 1443827 B1. 2007.

19. Nielsen PM. Meat based food product comprising lactobionic acid. European patent EP 1718169 B1. 2012.
20. Oe K, Kimura T. Recalcification promoter. Japanese patent JP2010006728 A. 2010.

21. Schaafsma G. Lactose and lactose derivatives as bioactive ingredients in human nutrition. Int Dairy J. 2008;18:458-65. https://doi.org/10.1016/j.idairyj.2007.11.013

22. Guerrero C, Vera C, Conejeros R, Illanes A. Transgalactosylation and hydrolytic activities of commercial preparations of $\beta$-galactosidase for the synthesis of prebiotic carbohydrates. Enzyme Microb Tech. 2015;70:9-17. https://doi.org/10.1016/j.enzmictec.2014.12.006

23. Giacomini C, Irazoqui G, Gonzalez P, Batista-Viera F, Brena BM. Enzymatic synthesis of galactosyl-xylose by Aspergillus oryzae $\beta$-galactosidase. J Mol Catal B: Enzym. 2002;1920:159-65. https://doi.org/10.1016/S1381-1177(02)00163-7

24. Klewicki R. Formation of gal-sorbitol during lactose hydrolysis with $\beta$-galactosidase. Food Chem. 2007;100:1196-201. https://doi.org/10.1016/j.foodchem.2005.10.064

25. Wei W, Qi D, Zhao H, Lu Z, Lv F, Bie X. Synthesis and characterisation of galactosyl glycerol by $\beta$-galactosidase catalysed reverse hydrolysis of galactose and glycerol. Food Chem. 2013;141:3085-92.

https://doi.org/10.1016/j.foodchem.2013.05.145

26. Carević M, Veličković D, Stojanović M, Milosavić N, Rogniaux $\mathrm{H}$, Ropartz D, Bezbradica D. Insight in the regioselective enzymatic transgalactosylation of salicin catalyzed by $\beta$-galactosidase from Aspergillus oryzae. Process Biochem. 2015;50:782-8.

https://doi.org/10.1016/j.procbio.2015.01.028

27. Lactozym. Product Sheet. Bagsvaerd, Denmark: Novozymes A/S; 2001;08279-01.

28. Torres DPM, Gonçalves MDPF, Teixeira JA, Rodrigues LR. Galacto-oligosaccharides, production, properties, applications, and significance as prebiotics. Compr Rev Food Sci Food Saf. 2010;9:438-54.

https://doi.org/10.1111/j.1541-4337.2010.00119.x

29. Shen Q, Yang R, Hua X, Ye F, Wang H, Zhao W, Wang K. Enzymatic synthesis and identification of oligosaccharides obtained by transgalactosylation of lactose in the presence of fructose using $\beta$-galactosidase from Kluyveromyces lactis. Food Chem. 2012;135:1547-54.

https://doi.org/10.1016/j.foodchem.2012.05.115

30. Iwasaki K, Nakajima M, Nakao S. Galacto-oligosaccharide production from lactose by an enzymic batch reaction using $\beta$-galactosidase. Process Biochem. 1996;31:69-76. https://doi.org/10.1016/0032-9592(94)00067-0

31. Klewicki R. Effect of selected parameters of lactose hydrolysis in the presence of $\beta$-galactosidase from various sources on the synthesis of galactosyl-polyol derivatives. Eng Life Sci. 2007;7:268-74.

https://doi.org/10.1002/elsc.200620185

32. Martínez-Villaluenga C, Cardelle-Cobas A, Corzo N, Olano A, Villamiel M. Optimization of conditions for galactooligosaccharide synthesis during lactose hydrolysis by $\beta$-galactosidase from Kluyveromyces lactis (Lactozym 3000 L HP G). Food Chem. 2008;107:258-64.

https://doi.org/10.1016/j.foodchem.2007.08.011

33. Zhou QZK, Chen XD. Effects of temperature and $\mathrm{pH}$ on the catalytic activity of the immobilized $\beta$-galactosidase from Kluyveromyces lactis. Biochem Eng J. 2001;9:33-40. https://doi.org/10.1016/S1369-703X(01)00118-8

34. Fortun Y, Colas B. Lithium chloride effect on phenylethyl- $\beta$ -D-galactoside synthesis by Aspergillus oryzae $\beta$-D-galactosidase in the presence of high lactose concentration. Biotechnol Lett. 1991;13:863-6.

https://doi.org/10.1007/BF01022087 
35. Rauter M, Schwarz M, Becker K, Baronian K, Bode R, Kunze G, Vorbrodt HM. Synthesis of benzyl $\beta$-D-galactopyranoside by transgalactosylation using a $\beta$-galactosidase produced by the over expression of the Kluyveromyces lactis LAC4 gene in Arxula adeninivorans. J Mol Catal B: Enzym. 2013;97:31927.

https://doi.org/10.1016/j.molcatb.2013.06.017

36. Pawlak-Szukalska A, Wanarska M, Popinigis AT, Kur J. A novel cold-active $\beta$-D-galactosidase with transglycosylation activity from the Antarctic Arthrobacter sp. 32cB - Gene cloning, purification and characterization. Process Biochem. 2014;49:2122-33.

https://doi.org/10.1016/j.procbio.2014.09.018
37. Iliev I, Vasileva T. Study of the transgalactosylation activity of $\beta$-galactosidase from a new strain Kluyveromyces lactis 3. J BioSci Biotech. 2012;1:149-53.

38. Goderska K, Juzwa W, Szwengiel A, Czarnecki Z. Lactobionic acid production by glucose-fructose oxidoreductase from Zymomonas mobilis expressed in Escherichia coli. Biotechnol Lett. 2015;37:2047-53. https://doi.org/10.1007/s10529-015-1887-0

39. Mäki-Arvela P, Murzina EV, Campo B, Heikkilä T, Leino AR, Kordas $\mathrm{K}$, et al. The effect of palladium dispersion and promoters on lactose oxidation kinetics. Res Chem Intermed. 2010;36:423-42.

https://doi.org/10.1007/s11164-010-0143-4 